\title{
CLINICAL STUDY OF PLACENTA ACCRETA SPECTRUM DISORDERS IN TERTIARY CARE HOSPITAL
}

KEY WORDS:

\section{Dr. Shrinivas Gadappa}

\section{Dr. Ankita Shah*}

\section{Dr. Rupali \\ Gaikwad}

\section{Dr. Susmita Pawar}

Professor and Head, Department of Obstetrics and Gynaecology, Government Medical College and Hospital, Aurangabad, Maharashtra, India- 431001.

Senior Resident, Department of Obstetrics and Gynaecology, Government Medical College and Hospital, Aurangabad, Maharashtra, India- 431001. *Corresponding Author

Assistant Professor, Department of Obstetrics and Gynaecology, Government Medical College and Hospital, Aurangabad, Maharashtra, India- 431001.

Department of Obstetrics and Gynaecology, Government Medical College and Hospital, Aurangabad, Maharashtra, India- 431001.

Aims And Objectives: To study the range of Placenta Accreta Spectrum (PAS) disorders, management of PAS, maternal outcome in PAS and post-operative complications in patients managed either by conservative or non-conservative management.

Methodology: Patient were diagnosed antenatally by 2D grey scale USG (ultrasonography) as PAS 0, 1,2 and 3 along with colour doppler studies. The decision of conservative versus non conservative management was taken by MDT (multidisciplinary team) along with the patients and relatives and after written and informed consent and elective surgery was planned between 34-35 weeks of gestation.

Results: Total number of cases studied over the period of 1 year were 45. On 2D gray scale USG, PAS 0 was seen in $60 \%$ followed by PAS 3 in $17.77 \%$ and only $6.66 \%$ of PAS 2 . According to weeks of gestation OH with IIAL (internal iliac ligation) was performed in $42.22 \%$ and $\mathrm{OH}$ without IIAL was performed in $37.77 \%$ and $20 \%$ patients who were managed by conservative method, 6 of them needed peripartum hysterectomy. Massive transfusion protocol was activated in all the cases.

Conclusion: The highest risk of placenta accreta spectrum disorders are amongst women whose pregnancy is complicated by placenta previa and with a prior scar on the uterus, due to the abnormal placental implantation on the scar site. The management of PAS disorders should be at tertiary care centre along with multidisciplinary care team.

\section{INTRODUCTION}

Placenta accreta was first described in the year 1937 by obstetrician Frederick C. Irving and pathologist Arthur T. Hertig. ${ }^{1}$

Over the past 40 years, caesarean delivery rates around the world have risen from less than $10 \%$ to over $30 \%$, thus simultaneously increasing the rate of placenta accreta spectrum (PAS) disorders. ${ }^{2}$ The incidence of PAS disorders have risen from 1 in 533 in 1998-2002 to 1 in 272 in $2016 .{ }^{3}$

The management of PAS has to be with adequate multidisciplinary team and at a tertiary care hospital to reduce the maternal mortality and morbidity. There is a wide variation on the management of PAS ranging from spectrum of conservative management to that of radical approach.

PAS disorders were defined by Luke et al. and divided into 3 categories

1. Adherent placenta accreta like creta, vera or adherentavilli simply adhere to myometrium

2. Placenta increta- when villi invade the myometrium

3. Placenta percreta- when villi invade the full thickness of myometrium including the serosa and sometimes the pelvic organs. ${ }^{6}$

The current hypothesis states that a defect of the endometrium-myometrial interface, typically at the site of a prior hysterotomy, leads to a failure of normal decidualization in that area, thus allowing extra villous trophoblastic infiltration and the villous tissue to develop deeply within the myometrium or at times even involving the pelvic organs.

Regarding prenatal diagnosis and screening ultrasound remains the most commonly used technique to diagnose PAS |www.worldwidejournals.com disorders. As no specific sign or set combination was diagnostic of adherent placenta, the European Working group on Abnormally Invasive Placenta (EW-AIP) an international expert group have proposed a standardized description of ultrasound signs which can be used for the diagnosis of PAS disorders.

The management of PAS has to be with adequate multi disciplinary team and at a tertiary care hospital to reduce the maternal mortality and morbidity. ${ }^{4}$ There is a wide variation on the management of PAS ranging from spectrum of conservative management to that of radical approach. ${ }^{5}$

Ours being a tertiary care hospital catering to high risk cases from the peripheral hospitals we have a lot of cases of Placenta accreta spectrum thus, we decided to analyse the spectrum of the placenta accreta disorder, maternal and neonatal outcome and management protocol by the multidisciplinary care team with the cycles of Massive transfusion protocol requirement at tertiary care hospital, Aurangabad.

\section{METHODS}

The duration of study was two year from May 2018-April 2020. Patient were diagnosed antenatally by 2D grey scale USG as PAS 0, 1,2 and 3 along with colour doppler studies. PAS 0placenta previa with no signs of invasion/placental lacuna PASl-presence of atleast 2 placental lacunae, loss of clear zone of bladder wall interruption. PAS2- PAS1 + uterovesical hypervascularity PAS3- PASl/PAS2 + e/o increased vascularity in inferior part of LUS (lower uterine segment), expanding to parametrial regions. Few cases were subjected to MRI (magnetic resonance imaging) when level of suspicion was high, only as an additional screening method. Elective 
surgery was planned between 34-35 weeks with consultation with the multidisciplinary care team (MDT) and after proper counselling of the patient and relative preoperatively to avoid emergency surgeries. The decision of conservative versus non conservative management was taken by MDT along with the patients and relatives and after written and informed consent.

The management of placenta accreta aims at reducing the maternal morbidity and mortality associated with massive obstetric haemorrhage. Due to lack of resources and research related to the management of accreta a non-conservative approach is used by most of the tertiary care centres. Hysterectomy by far remains the most definitive surgical treatment for PAS disorders, especially for its invasive forms and a primary elective caesarean hysterectomy is safest and most practical approach for low- and middle- income countries where follow-up could be a major problem and adjunctive treatment options are not available.

The conservative method in management of Placenta Accreta Spectrum disorders include "Leaving placenta IN SITU" approach, Triple-P procedure and one step conservative surgery. The overall success rate of uterine preservation with the above mentioned technique is $78 \%$ and related to severe maternal morbidity.

The massive transfusion protocol was activated in all the cases and the protocol followed was 1:1:1 for PRBC(packed red blood cells):platelet:FFP(fresh frozen plasma). It helps in preventing dilutional coagulopathy and intra-operative and post-operative morbidity.

The MDT has to be backed up with good surgical expertise in complex pelvic surgery. The components of MDT are enumerated as below access to MDT care team $24 / 7$ access to the care team, standard care plan, radiologic expertise for diagnosis, senior obstetrician, surgical expertise for complex surgery- urogynaecologist, anaesthetist, NICU (neonatal intensive care unit) facility, ICU (intensive care unit) and massive transfusion capacity.

Patients diagnosed in the intrapartum period were managed with counselling of the relative and most were managed by obstetric hysterectomy. Post-operative complications were noted and analysed based on conservative and nonconservative management. Specimen of uterus was sent for histopathology examination after obstetric hysterectomy.

\section{AIMS AND OBJECTIVES}

- To study the range of Placenta Accreta Spectrum (PAS) disorders

- To study the management of Placenta Accreta Spectrum (PAS)

-To study the maternal outcome in Placenta Accreta Spectrum (PAS)

- To study the post-operative complications in patients managed either by conservative or non-conservative management.

\section{Inclusion Criteria}

All patients presenting with antenatal documentation of placenta accreta spectrum or presenting at the time of caesarean section.

Patients who consented for the study.

\section{Exclusion Criteria}

Patients managed outside and referred for further management.

Patients not consenting for the study.

The data was compiled and analysed using descriptive statistics i.e. Rates and proportions. Mean and standard deviation were used for continuous variables.

\section{RESULTS}

This retrospective cross-sectional study conducted on 45 cases of PAS yielded the following results.

Table 1 - Distribution Of Cases According To 2D Grayscale USG

\begin{tabular}{|l|l|l|}
\hline & No of patients & $\%$ \\
\hline PAS $* 0$ & 27 & 60 \\
\hline PAS 1 & 07 & 15.55 \\
\hline PAS 2 & 03 & 6.66 \\
\hline PAS 3 & 08 & 17.77 \\
\hline
\end{tabular}

PAS* 0- placenta previa with no signs of invasion/placental lacuna PAS1- presence of atleast 2 placental lacunae,loss of clear zone of bladder wall interruption PAS2- PAS1 + uterovesical hypervascularity PAS3- PAS1/PAS2 + e/o increased vascularity in inferior part of LUS, expanding to parametrial regions.

On 2D gray scale USG, PAS 0 was seen in majority of the cases i.e $27(60 \%)$ followed by PAS 3 in 8 cases $(17.77 \%)$ and only 3 cases $(6.66 \%)$ of PAS 2 .

Table 2 - Distribution According ToWeeks Of Gestation

\begin{tabular}{|l|l|l|}
\hline Gestational Age & No. of cases & Percentage \\
\hline$<20$ weeks & 01 & 2.22 \\
\hline $20-37$ weeks & 31 & 68.89 \\
\hline$>37$ weeks & 13 & 28.89 \\
\hline Total & 45 & \\
\hline
\end{tabular}

At the time of admission, gestational age in majority of the cases i.e. 31 (68.89) was between 20-37 weeks, followed by 37 weeks or more in 13 cases (28.89) and less than 20 weeks in only one case (2.22).

Table 3- Distribution According To Symptoms On Admission

\begin{tabular}{|l|l|l|l|}
\hline Presentation & $\begin{array}{l}<37 \\
\text { weeks }\end{array}$ & $\begin{array}{l}\mathbf{> 3 7} \\
\text { weelks }\end{array}$ & Total \\
\hline No symptoms with USG S/O PAS & 16 & 02 & $18(40 \%)$ \\
\hline Antepartum bleeding & 04 & 03 & $07(15.56 \%)$ \\
\hline Intrapartum bleeding & 12 & 08 & $20(44.44 \%)$ \\
\hline Total & 32 & 13 & 45 \\
\hline
\end{tabular}

On admission, distribution of cases according to symptoms with gestational age was compared and it was seen that patients $<37$ weeks with no symptoms but with USG s/o of PAS were 16 and $>37$ weeks were 02 accounting to total 18 cases (40\%). Most of the cases i.e. 20 (44.44\%) were diagnosed due to intrapartum bleeding. 11 cases were $<37$ weeks and 9 cases were $>37$ weeks. Cases which presented with antepartum bleeding were 7 (15.56\%).

Table 4 - Distribution according to HIGH RISK* factors

\begin{tabular}{|l|l|l|l|l|}
\hline & $\begin{array}{l}\text { Placenta } \\
\text { accreta }\end{array}$ & $\begin{array}{l}\text { Placenta } \\
\text { increta }\end{array}$ & $\begin{array}{l}\text { Placenta } \\
\text { percreta }\end{array}$ & Total \\
\hline $\begin{array}{l}\text { Previous 1 } \\
\text { LSCS }\end{array}$ & 10 & 03 & 05 & $18(40 \%)$ \\
\hline $\begin{array}{l}\text { Previous 2 } \\
\text { LSCS }\end{array}$ & 09 & 03 & 03 & $15(33.33 \%)$ \\
\hline $\begin{array}{l}\text { Previous 3 } \\
\text { LSCS }\end{array}$ & 02 & 01 & 02 & $05(11.11 \%)$ \\
\hline $\begin{array}{l}\text { Previous } \\
\text { abortions } \\
\text { with h/o } \\
\text { curettage }\end{array}$ & 05 & 01 & 01 & $07(15.56 \%)$ \\
\hline Total & 26 & 08 & 11 & 45 \\
\hline
\end{tabular}

*No cases were seen with previous myomectomy.

When number of LSCS(lower segment caesarean section) is 
compared to the incidence of placenta accreta spectrum disorders maximum cases i.e. $18(40 \%)$ cases were seen with previous 1 LSCS, followed by $15(33.33 \%)$ cases were seen in patients with previous 2 LSCS. 7 cases $(15.56 \%)$ were observed in patients with previous abortions with $\mathrm{H} / \mathrm{O}$ (history of) curettage.

Table 5- Distribution According To Management When Compared ToWeeks Of Gestation

\begin{tabular}{|l|l|l|l|}
\hline Gestational Age & OH without IIAL & $\begin{array}{l}\text { OH with } \\
\text { IIAL }\end{array}$ & $\begin{array}{l}\text { Conservative } \\
\text { management after } \\
\text { CS } \\
\text { (classical section) }\end{array}$ \\
\hline$<20$ weeks & 01 & 00 & 00 \\
\hline $20-37$ weeks & 11 & 12 & 08 \\
\hline$>37$ weeks & 05 & 07 & 01 \\
\hline Total & $17(37.77 \%)$ & $19(42.22 \%)$ & $09^{*}(20 \%)$ \\
\hline
\end{tabular}

*out of 9 cases managed conservatively, 6 cases underwent peripartum hysterectomy.

When management of the patients was compared to weeks of gestation OH(obstetric hysterectomy) with IIAL (internal iliac artery ligation) was performed in 19 cases $(42.22 \%)$ and $\mathrm{OH}$ without IIAL was performed in 17 cases (37.77\%) and out of 9 $(20 \%)$ patients who were managed by conservative method, 6 of them needed peripartum hysterectomy.

Conservative management was performed in 8 cases between 20-37 weeks of gestation and only one case was $>37$ weeks of gestation.

Table 6-Distribution Of Cases On Basis Of Management With Hemoglobin Levels And MTP Cycles

\begin{tabular}{|c|c|c|c|c|c|c|}
\hline & & $\begin{array}{l}1^{\text {st }} \text { cycle } \\
\text { of IMTP }\end{array}$ & \begin{tabular}{|l|}
$2^{\text {nd }}$ \\
cycle \\
of \\
MTP \\
\end{tabular} & $\begin{array}{l}3^{\text {rd }} \text { cycle } \\
\text { of } \mathrm{MTP}\end{array}$ & \begin{tabular}{|l|} 
Mean \\
Preop \\
Hb \\
(g/dl) \\
\end{tabular} & $\begin{array}{l}\text { Mean } \\
\text { postop } \\
\text { Hb } \\
\text { (g/dl) }\end{array}$ \\
\hline \multirow[t]{2}{*}{$\begin{array}{l}\text { OH+ } \\
\text { IIAL }\end{array}$} & Elective(11) & 07 & 04 & & $\begin{array}{l}10.4 \pm \\
2.1\end{array}$ & $\begin{array}{l}9.8 \pm \\
1.6\end{array}$ \\
\hline & \begin{tabular}{|l|} 
Emergency \\
$(08)$
\end{tabular} & & 05 & $\begin{array}{l}03 \\
(6.6 \%)\end{array}$ & $\begin{array}{l}8.4 \pm \\
1.3\end{array}$ & $\begin{array}{l}9.1 \pm \\
1.5\end{array}$ \\
\hline \multirow[t]{2}{*}{$\mathrm{OH}$} & Elective(7) & 05 & 02 & 00 & $\begin{array}{l}10 \pm \\
1.8 \\
\end{array}$ & \begin{tabular}{|l|}
10.2 \\
\pm 1.2 \\
\end{tabular} \\
\hline & \begin{tabular}{|l|}
$\begin{array}{l}\text { Emergency } \\
(10)\end{array}$ \\
\end{tabular} & 02 & 05 & \begin{tabular}{|l|}
03 \\
$(6.6 \%)$ \\
\end{tabular} & \begin{tabular}{|l|}
$8.2 \pm$ \\
1.4 \\
\end{tabular} & \begin{tabular}{|l|}
$8.8 \pm$ \\
1.4 \\
\end{tabular} \\
\hline $\begin{array}{l}\text { Cons } \\
\text { ervat } \\
\text { ive } \\
\text { man } \\
\text { age } \\
\text { ment }\end{array}$ & & 03 & 02 & 04 & \begin{tabular}{|l|}
$10.8 \pm$ \\
1.4
\end{tabular} & $\begin{array}{l}11.2 \\
\pm 1.6\end{array}$ \\
\hline Total & & \begin{tabular}{|l}
17 \\
$(37.77 \%)$
\end{tabular} & \begin{tabular}{|l|}
18 \\
$(40 \%)$
\end{tabular} & \begin{tabular}{|l|}
10 \\
$(22.22 \%)$
\end{tabular} & & \\
\hline
\end{tabular}

Massive Transfusion Protocols (MTP) were activated for all the cases. Maximum patients $18(40 \%)$ required 2 cycles of MTP and 10 patients $22.22 \%$ required 3 cycles of MTP OF which 4 patients were from conservative group with later required peripartum hysterectomy. Patients who were managed only by $\mathrm{OH}$ and where taken as emergency procedure had mean pre-op $\mathrm{Hb}$ of 8.2 and post-op $\mathrm{Hb}$ of 8.8 whereas patients managed by $\mathrm{OH}$ with IIAL and taken as elective procedure, 7 required just one cycle of MTP and 4 required 2 cycles of MTP. The mean pre-op $\mathrm{Hb}$ in elective group was $10.4 \%$ and in emergency group was $8.4 \%$ and mean post-op Hb was 9.8 and $9.1 \mathrm{~g} / \mathrm{dl}$ in elective and emergency group respectively.

*4 neonatal deaths due to extreme prematurity and low birth weight.

Table 7- Distribution According To Post-operative Complications

\begin{tabular}{|l|l|}
\hline Post-operative complications & Number of Patients \\
\hline Bladder injury & $1(2.22 \%)$ \\
\hline
\end{tabular}

\begin{tabular}{|l|l|}
\hline Post-operative fever & $7(15.6 \%)$ \\
\hline Surgical site infection & $3(6.66 \%)$ \\
\hline Acute kidney injury(AKI) & $3(6.66 \%)$ \\
\hline Maternal mortality & $1(2.22 \%)$ \\
\hline
\end{tabular}

Admission to ICU was seen in 18 cases (40\%), of which 12 cases where prophylactically shifted to ICU.

Bladder was injured in one case intraoperatively. Post operatively 17 cases ( $15.65 \%)$ developed fever and $3(6.66 \%)$ had surgical site infection. 3 patients developed AKI of which required multiple cycles of dialysis. Mortality occurred in 1 case $(2.22 \%)$ as patient was referred late in bleeding phase and diagnosed on table as accreta and died of AKI (acute kidney injury) on Day 7.

Table 8- Distribution Of Cases According To Depth Of Invasion (histopathology Report)

\begin{tabular}{|l|l|}
\hline PAS & \\
\hline Placenta Accreta & $27(60 \%)$ \\
\hline Placenta Increta & $7(15.56 \%)$ \\
\hline Placenta Percreta & $11(24.44 \%)$ \\
\hline
\end{tabular}

Cases of PAS were classified based on depth of myometrial invasion on histopathological examination. Of the 45 cases, Placenta Accreta was seen it 27 cases (60\%), Placenta Increta in 7 cases $(15.56 \%)$ and Placenta Percreta in 11 cases $(24.44 \%)$.

\section{DISCUSSION}

In 2019, G.Cali et al in a retrospective analysis of prenatal ultrasound staging system for placenta accrete spectrum disorders found $57 \%$ patients of PAS showing PAS 0 features on USG greyscale classification, $15 \%$ showed PASl features, $6 \%$ PAS2 and 20\% PAS 3. Our study showed similar findings$57 \%$ patients showed PAS $0,15 \%$ PASl, $7 \%$ PAS 2 and $18 \%$ showed PAS 3 features.

Eric Jauniaux et al in 2019 conducted a meta-analytic study on the prevalence and outcomes of placenta accreta spectrum and found the prevalence of placenta accreta to be around $62.5 \%$ which was close to the prevalence that we found in our study $(60 \%)^{8}$

In 2020 , Imtiaz et al, in a retrospective cohort study on comparison of antenatally and intraoperatively diagnosed cases of placenta accreta spectrum found that $64.6 \%$ cases were diagnosed intraoperative, in our study we found it to be similar i.e around $61 \%{ }^{9}$

A study conducted by O'Brien JM et al showed that management included surgical removal of the uterus(101 cases, 93\%) and conservative treatment with the placenta left in situ after delivery (8 cases, 7\%).7In our study surgical management was done in 36 cases ( $81.25 \%$ ) and conservative management was opted for in 9 cases(18.75\%), eventually 6 out of the 9 managed conservatively needed hysterectomy accounting to $93 \%$ of total cases managed surgically. ${ }^{10}$

According to a study conducted by KE Fitzpatrick et al, among women with a confirmed pathological diagnosis, $60 \%(41 / 68)$ of cases were accreta, $9 \%(6 / 68)$ were increta, and $31 \%$ $(21 / 68)$ were percreta. Our study showed $60 \%(27 / 45)$ incidence of accreta, $15 \%$ (7/45) incidence of increta and $24 \%$ $(11 / 45)$ incidence of percreta. ${ }^{11}$

In $2008 \mathrm{P}$. Tantbirojn et al in their study showed the incidence of PAS in previous 1,2 and 3 LSCS and previous H/o curettage respectively and found incidence of PAS in previous 1 LSCS to be $32 \%$, previous 2 LSCS also $32 \%, 23 \%$ in previous 3 LSCS and $10 \%$ in patients with $\mathrm{H} / \mathrm{O}$ previous curettage. In our study the incidence of PAS was $40 \%, 33 \%, 11 \%$ and $16 \%$ in previous 1 LSCS, previous 2 LSCS, previous 3 LSCS and previous H/o curettage respectively. ${ }^{12}$ 
The massive transfusion protocol was activated in all the cases. The traditional definition of MTP constituted of supplying $>10$ units of RBC's within 24 hours but we have followed the rule of $2: 1: 1$ wherein 2 PRBC's were given for 1 FFP and 1 platelet to avoid dilutional coagulopathy. Risk of haemorrhage was anticipated well in advance and MTP cycles were initiated at the earliest signs of shock. ${ }^{13}$

\section{CONCLUSION}

The highest risk of placenta accreta spectrum disorders are amongst women whose pregnancy is complicated by placenta previa and with a prior scar on the uterus, due to the abnormal placental implantation on the scar site. On 2D gray scale USG, specificity is highest $(99.8 \%$ ) with abnormalities of uterus and bladder interface and sensitivity is highest with colour doppler abnormalities (90.8\%). MRI is to be used as a complementary method only when patients have high index of suspicion with 2D Gray scale USG. The time of delivery to be individualised but when there is antepartum diagnosis of PAS elective procedure to be planned between 34-35 weeks of gestation. Planned caesarean hysterectomy rather than conservative procedures are preferred to avoid sepsis and peripartum hysterectomy. Massive transfusion protocol to be activated in all the cases. The choice of conservative versus non-conservative management is to be individualised along with consultation of multidisciplinary care team but as maximum cases of conservative management require peripartum hysterectomy increasing the morbidity of the mother. Classical caesarean section followed by obstetric hysterectomy is the treatment of choice. Conservative management should only be offered after proper patient counselling, in low-resourse setting and when rigorous follow-up is possible for the mother. Team approach in the management of PAS is gold standard.

\section{REFERENCES}

1. Irving FC, Hertig AT. A study of placenta accreta. Surg gynec obstet. 1937;64:178-200

2. Solheim KN, Esakoff TF, Little SE, Cheng YW, Sparks TN, Caughey AB. The effect of caesarean delivery rates on the future incidence of placenta previa, placenta accreta and maternal mortality. J Matern Fetal Neonatal Med.2011;24:1341-1346

3. Placenta accreta spectrum. Obstetric care consensus no. 7. American College of Obstetricians and Gynecologists. Obstet Gynecol 2018;132:e25975

4. Eller AG, Bennett MA, Sharshiner M, et al. Maternal morbidity in cases of placenta accreta managed by a multidisciplinary care team compared with standard obstetric care. Obstet Gynecol.201 1;117:331-7

5. Allen L, Jauniaux E, Hobson S, Paillon- Smith J, Belfort MA FIGO Placenta Accreta Diagnosis and Management Expert Consensus Panel. FIGO consensus guidelines on placenta accreta spectrum disorders: Nonconservative surgical management. Int J Gynecol Obstet.2018;140:281Noncons
290

6. Luke RK, Sharpe JW, Greene RR. Placenta accreta: the adherent or invasive placenta.Am JObstet Gynecol.1966;95:660-668

7. G. Calí,I.E.Timor-Tritsch, F. Forlani,J. Palacios-Jaraquemada, A. Monteagudo, A. Kaelin Agten, M. E. Flacco, A. Khalil, D. Buca, L. Manzoli, M. Liberati, F. D'Antonio, Value of first-trimester ultrasound in prediction of third-trimester sonographic stage of placenta accreta spectrum disorder and surgical outcome, Ultrasound in Obstetrics \& Gynecology, 10.1002/uog.21939, 55, 4, (450-459), (2019).

8. Jauniaux E, Bunce C, Grønbeck L, Langhoff-Roos J. Prevalence and main outcomes of placenta accreta spectrum: a systematic review and metaanalysis. Am J Obstet Gynecol.2019;221(3):208-218.

9. Imtiaz R, Masood Z, Husain S, Husain S, Izhar R, Hussain S. A comparison of antenatally and intraoperatively diagnosed cases of placenta accreta spectrum.J Turk Ger Gynecol Assoc 2020;21:84-89

10. O'Brien JM, Barton JR, Donaldson ES. The management of placenta percreta: conservative and operative strategies. Am J Obstet Gynecol 1996;175:1632-8

11. Fitzpatrick KE,Sellers S, Spark Pet al; The Management and outcomes of placenta accreta, increta, and percreta in the population based descriptive study.BJOG 2014;121:62-71

12. Tantbirojn, P., Crum, C. P., \& Parast, M. M. (2008). Pathophysiology of Placenta Creta: The Role of Decidua and Extravillous Trophoblast. Placenta, 2008; 29(7),639-645.

13. Gatta L.A., Evelyn L.,Lockhart, James A.H., Blood products in management of Abnormal Placentation. Clinical Obstetrics and Gynecology 2018;61(4),828840 . 